\title{
Electrical signatures of the Earth's crust in central India as inferred from magnetotelluric study
}

\author{
G. Dhanunjaya Naidu*, K. Veeraswamy, and T. Harinarayana \\ CSIR—National Geophysical Research Institute, Hyderabad, India
}

(Received January 27, 2010; Revised June 14, 2011; Accepted August 4, 2011; Online published February 21, 2012)

\begin{abstract}
The tectonic scenario of the Narmada-Son Lineament (NSL) zone has been the subject of debate for the last few decades. It is characterized tectonically as a highly-disturbed zone in Indian geology since Precambrian times. A magnetotelluric (MT) study has been carried out across the NSL zone along a 270-km-long N-S-trending traverse, extending from Hoshangabad in the North to Ner in the South. As a part of the present study, 25 magnetotelluric soundings have been collected and the data rotated to $\mathrm{N} 70^{\circ} \mathrm{E}$ after removing local distortions, arising from $3 \mathrm{D}$ galvanic effects, using the Groom-Bailey decomposition technique. 2-D inversion has been carried out using an NLCG scheme. The results derived from the 2-D inversion have brought out the highly conductive nature of the mid-lower crust at places coinciding with the known faults. The significant high heat flow and seismicity in the region associated with these faults may be caused by tectonic activity and the highly conductive nature of the mid-lower crust. This may be due to the partial melting of subsurface rocks resulting from the high temperature caused by mantle upwarping in the region. The results are also compared with the gravity and a nearby Deep Seismic Sounding (DSS).
\end{abstract}

Key words: Magnetotellurics, deep crust, Narmada-Tapti region, electrical conductivity, seismotectonics.

\section{Introduction}

The Narmada-Son Lineament (NSL) is a late Archean mega geo-fracture extending for about $1200 \mathrm{~km}$ across the Indian peninsula in the E-W/ENE-WSW direction. Tectonically, this lineament is highly disturbed and reactivation of this lineament is believed to be due to the collision of the Indian plate with the Eurasian plate. As a result, the rigid continental crust has broken down along the pre-existing fracture system (Jain et al., 1984). Detailed geological studies of the region have been reported (West, 1962; Wellman and Mc Elhinny, 1970; Ghosh, 1976 etc.). The origin of the lineament is believed to have been formed in two distinctly different periods-after the commencement of the eruption of the Deccan traps, and the period prior to it. From various geological studies, this lineament is shown to be situated close to the zones of fractures belonging to early Precambrian, Cretaceous and post-Deccan trap period. The Narmada valley dates back predominantly to the pre-Deccan trap period. Although the tectonic movements began significantly before the Deccan traps, it is still active as is attested by the number of earthquakes reported along the lineament (Ramalingeswara Rao and Sitapathi Rao, 1984).

Though several geophysical studies have been carried out

\footnotetext{
*Now at Central Water and Power Research Station, Ministry of Water Resources, Pune, India.

${ }^{\dagger}$ Now at Gujarat Energy Research and Management Institute (GERMI) Research Centre, Gandhinagar, Gujarat, India 382007.

Copyright (c) The Society of Geomagnetism and Earth, Planetary and Space Sciences (SGEPSS); The Seismological Society of Japan; The Volcanological Society of Japan; The Geodetic Society of Japan; The Japanese Society for Planetary Sciences; TERRAPUB.
}

doi:10.5047/eps.2011.08.004 earlier (Kaila et al., 1985; Verma and Banerjee, 1992; Singh and Meissner, 1995; Tewari and Prakash Kumar, 2003; Mall et al., 2005) including MT studies (Gokarn et al., 2001; Rao et al., 2004; Patro et al., 2005; Harinarayana et al., 2007; Naidu and Harinarayana, 2009) to understand the tectonic scenario of the lineament, the present study has been undertaken in order to add value to the earlier results. A major contribution from the present study is to understand the nature of the crust and mantle structure more clearly and also to examine the electrical signatures of the surface mapped faults such as the Narmada South Fault (NSF), Tapti Fault (TF), Gavligarh Fault (GF) and Purna Fault (PF), etc. The present study has been carried out along a N-S-trending traverse, with a total of 25 MT sites, of about $270-\mathrm{km}$ long from Hoshangabad towards the north to Ner towards the south. The traverse cuts across the major faults mentioned above and various geological formations of different ages, as shown in Fig. 1.

\section{Data Analysis}

The MT data were collected using an ADU-06 (Metronix) in the frequency range of 1000-0.001 Hz. In order to obtain MT impedance tensor and magnetic transfer functions, robust single-station processing to down-weigh or discard outliers of impedance estimates was used at each frequency in the band of measurement (Jupp and Vozoff, 1997). A typical example of the MT impedance tensor data is shown in Fig. 2(a).

In order to obtain the strike angle free from near surface distortions, the impedance tensors at each site for all frequencies were decomposed using the Groom-Bailey decomposition method (Groom and Bailey, 1989). The 


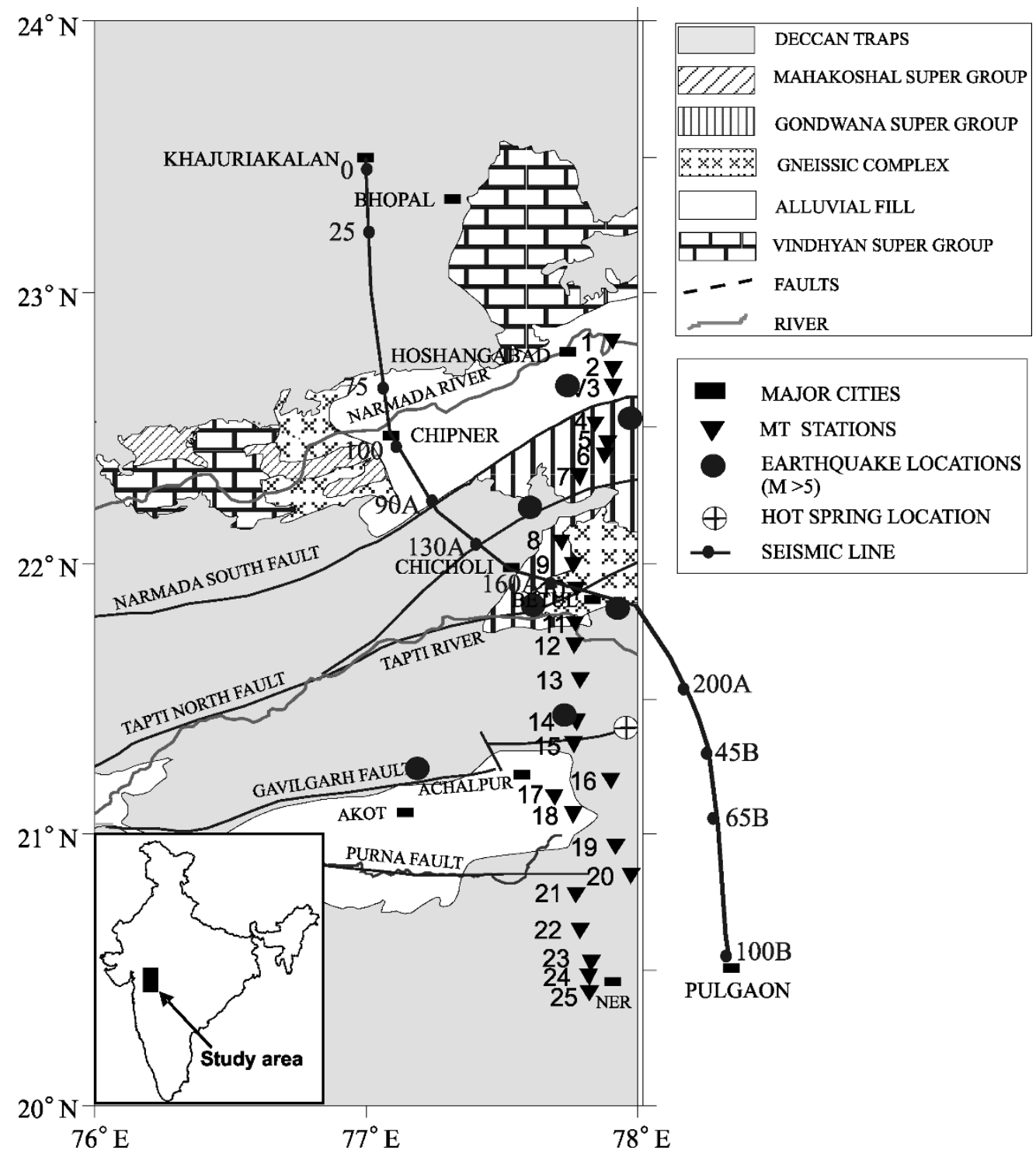

Fig. 1. Location of the Hoshangabad-Ner traverse (MT soundings are black triangles) plotted on a geological and tectonic map of the present study area (GSI, 2000). The black solid line is the seismic line from Khajuriakalan $\left(23.5^{\circ} \mathrm{N}, 77^{\circ} \mathrm{E}\right)$ to Pulgaon $\left(20.75^{\circ} \mathrm{N}, 78.25^{\circ} \mathrm{E}\right)$.

impedance tensors for all frequencies (eight frequencies per decade and forty frequencies in five decades) at each site were rotated at intervals of $5^{\circ}$ to obtain the shear and twist for each rotation. This determines the frequency invariant values of the shear and twist and also the range of the strike angles over which these parameters are reasonably stable. The shear and twist values obtained at each site were fixed and the unconstrained strike angles were obtained at each frequency for all the sites. The strike has a weak dependence on the twist and shear and thus such large variations are not unusual. The regional strike is constrained in the range of $\mathrm{N} 55^{\circ} \mathrm{E}$ and $\mathrm{N} 80^{\circ} \mathrm{E}$ over a range of frequencies $(100-0.001 \mathrm{~Hz})$ for all the sites, and a regional strike of $\mathrm{N} 70^{\circ} \mathrm{E}$ is observed to be the best-fitting strike for most of the sites in the close vicinity of the major tectonic elements, as shown in the rose diagram (Fig. 2(b)). This suggests a regional strike direction of $\mathrm{N} 70^{\circ} \mathrm{E}$. In an earlier study (Patro et al., 2005), a nearby MT traverse located parallel to the present traverse, $\mathrm{N} 75^{\circ} \mathrm{E}$, is also obtained as a geo-electric strike. The apparent resistivity and phase along this di- rection are aligned to the TE-mode (electrical field parallel to the strike) and as the TM-mode (electrical field perpendicular to the strike). In the present study, the dimensionality indicator is estimated from the measured impedance tensor data. The observed Swift (Swift, 1967) and Bahr (Bahr, 1988) skew values fall below 0.3 for the majority of the frequencies ranging from $1000-0.001 \mathrm{~Hz}$, as shown in Fig. 3(a), thus indicating the 2-D subsurface structure. Hence, the subsurface structure is assumed to be 2-D for further analysis.

\section{2-D Inversion Results}

The 2-D inversion has been carried out using the Rodi and Mackie's (2001) RLM2DI code, as implemented in the WinGLink software package. This finds regularized solutions (Tikhonov Regularization) to the two-dimensional inverse problem for MT data using the method of nonlinear conjugate gradients (NLCG) to minimize an objective function that penalizes data residuals and second spatial derivatives of resistivity. 
(a)
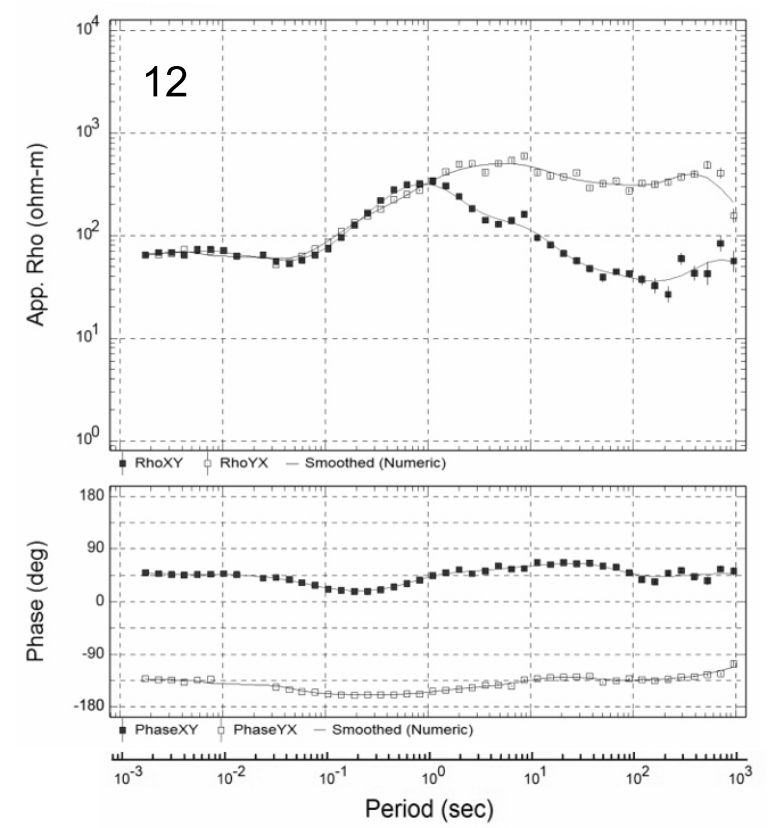

(b)

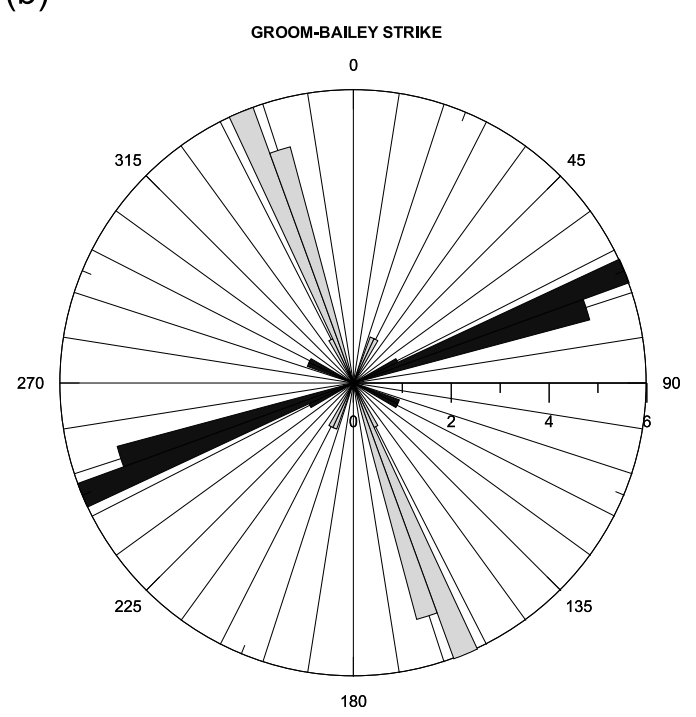

Fig. 2. (a) A typical example of MT data for station 12. (b) Best fitted regional strike direction of $\mathrm{N} 70^{\circ} \mathrm{E}$ and its $90^{\circ}$ ambiguity $\mathrm{N} 20^{\circ} \mathrm{W}$ are plotted using the Groom-Bailey decomposition technique (Rose diagram) in the frequency range of 100-0.001 Hz considering all the stations.

The trade-off parameter " $\tau$ " represents a measure of compromise between data fit and model smoothness. To find a suitable value of " $\tau$ ", the inversion procedure is repeated with different $\tau$ values of 5,10,15.....50, 100 and an L curve (Hansen, 1998) is plotted between model roughness and rms error. The value corresponding to the corner of the curve (in our case, $\tau=10$ ) is considered to be the most appropriate for the model shown in Fig. 3(b). The inversion process was repeated with different starting models (homogeneous half space) of 50, 100, 500 and 1000 ohm$\mathrm{m}$ and, for the final model, a resistivity of $100 \mathrm{ohm}-\mathrm{m}$ was set. Error floors of $20 \%$ for the apparent resistivity and 5\% $\left(1.5^{\circ}\right)$ for the phase were assigned, thus down-weighing the apparent resistivity with respect to phase in minimizing the static shift effect on apparent resistivity. The root-meansquare (RMS) fit indicates the misfit between the observed and modeled data as a percentage. Here, the value of the misfit is $2.25 \%$ for the derived model after 100 iterations. Beyond this, the RMS misfit remained constant.

\section{2-D Geo-electric Crustal Structure}

A 2-D geo-electric section derived from 2-D inversion is presented in Fig. 4(b). The geo-electric section is characterized by several less-resistive to high-resistive features all along the traverse. A basin like structure with thin trap and sediments is clearly delineated with a resistivity of the order of 50-100 ohm-m at shallow crustal depths followed by a high-resistive ( $>1000 \mathrm{ohm}-\mathrm{m}$ ) basement between the stations 12 and 20. The high-resistive basement is exposed near the Tapti fault, where the older rocks of Archaean age are mapped (Fig. 4(b)). The high-resistive upper crust is thin towards the north of the Tapti fault and thickens towards the southern side of the traverse.

Towards the north, the thin high-resistive (500-5000 ohm-m) upper crust and the anomalously conductive (1$30 \mathrm{ohm}-\mathrm{m}$ ) nature of the mid crust (A) in Fig. 4(b) and the seismicity near the Narmada south fault are pointers to the tectonic activity in the region. The two other conductive features, B and C (Fig. 4(b)), are also observed between the Tapti and Gavligarh faults as well as the Gavligarh and Purna faults. The lower crust is characterized by a conductive (1-30 ohm-m), to a moderately resistive $(50-200 \mathrm{ohm}-$ $\mathrm{m})$, nature. The results of the MT study in the form of the geo-electric section are compared with nearby Deep Seismic Sounding (DSS) and the regional Bouguer gravity data (NGRI, 2006) as shown in Fig. 4. The gravity values are taken for each station by digitizing the gravity map (NGRI, 2006). A maximum value of $-25 \mathrm{mGal}$ at station 9 is observed and maintains a value of about $-40 \mathrm{mGal}$ towards the southern end of the traverse, while small highs and lows are caused by local features (Fig. 4(a)). A steep fall in the gravity is observed near station 7 , where it has a minimum value of $-70 \mathrm{mGal}$. A small gravity high is observed between stations 4 and 6 . This is probably caused by a local feature. The Narmada South fault (NSF) is located between stations 3 and 4, whereas the Tapti North fault (TNF) is located close to station 7 . We can find a minimum gravity value of about $-70 \mathrm{mGal}$ at both the faults. The MT traverse passes nearer to the earlier Deep Seismic Sounding profile (Kaila et al., 1985) from Khajuria Kalan $\left(23.5^{\circ} \mathrm{N}\right.$, $\left.77^{\circ} \mathrm{E}\right)$ to Pulgaon $\left(20.75^{\circ} \mathrm{N}, 78.25^{\circ} \mathrm{E}\right)$. The seismic section along the MT traverse is presented in Fig. 4(c).

The data fit for observed and calculated values is shown in the form of pseudo-sections for all the stations (Fig. 5). The data fit for observed and calculated values for representative sites for both TE and TM are shown in Fig. 6. 


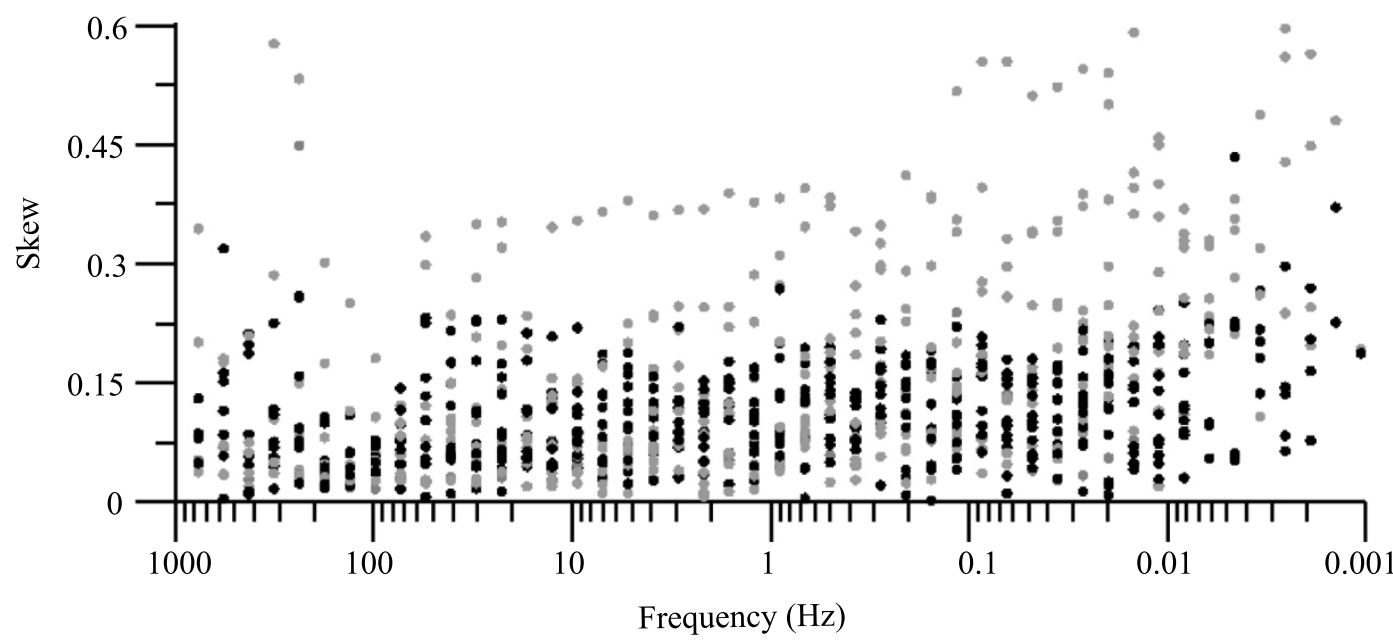

- Swift's skew

- Bahr's skew

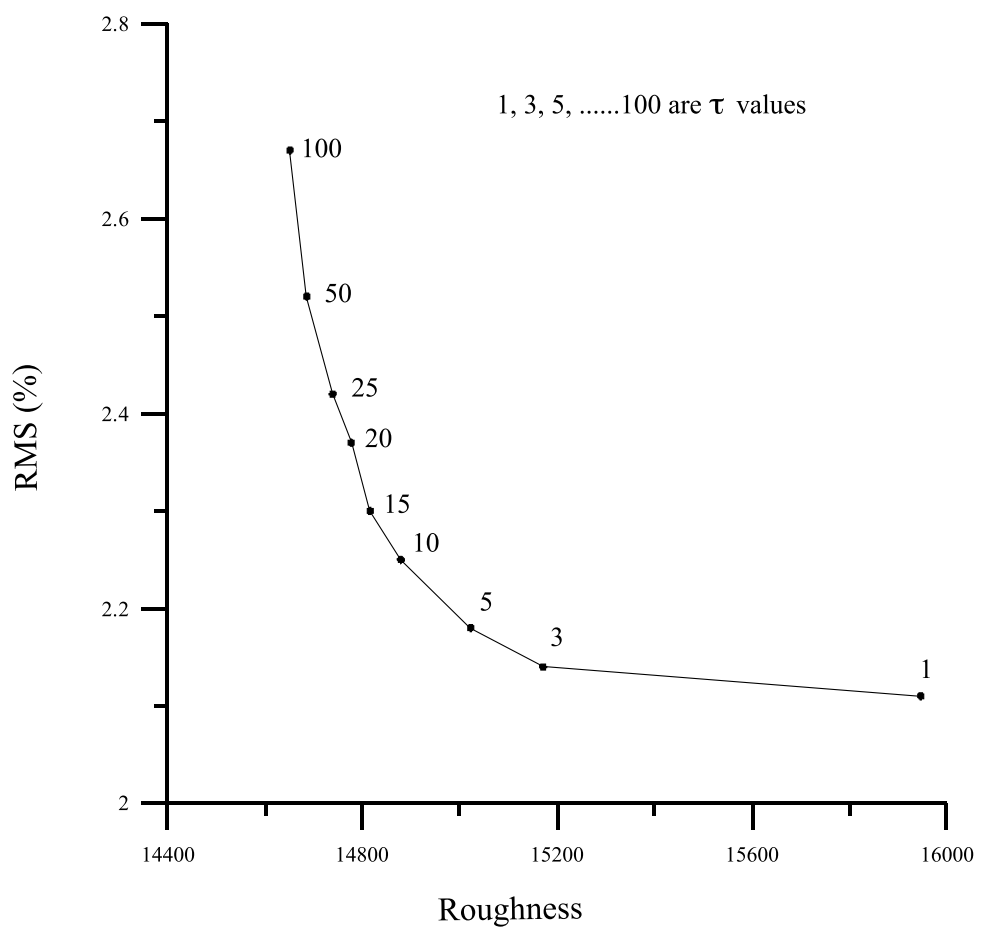

Fig. 3. (a) Dimensionality parameters (Swift's and Bahr's skew) are plotted for the present data set. Dots in a grey color indicate the Swift skew whereas dots in black indicate the Bahr's skew. (b) The rms error in percentage is plotted against model roughness to obtain the trade-off parameter (Hansen, 1998). Optimal trade-off parameter $\tau=10$ is chosen.

\section{Discussion and Conclusions}

There have been few MT studies carried out in central India over the Deccan volcanic province across the major fault zones. A recent study by Naganjaneyulu and Santosh (2010) identified the highly-conductive bodies as mafic/ultra mafic layered intrusives in the central India tectonic zone (CITZ), and also they have proposed a doublesided subduction history along the CITZ. Patro and Sarma (2009) identified a two-layered lithospheric mantle structure of this region describing a highly-resistive nature of the lithospheric structure on the top, and a low resistive nature at the bottom. In addition, other studies by Naidu and Harinarayana (2009), Gokarn et al. (2001), and Rao et al. (2004) have identified anomalous conductive features at mid-lower crustal depths, through various factors such as partial melts, fluids, etc., in the same region. However, anomalous conductive features associated with significant seismicity is not discussed in detail in the previous studies. Hence, the present study confirms anomalous conductive features in the region, and also proposes that the relation between seismicity and conductivity is of relevance to understand the earthquake mechanism.

The present MT study infers that a basin-like structure with thin trap and buried sediments is identified at shallow crustal depths, confined between the stations 12 (close to the Tapti fault) and 20 (close to the Purna fault) in the geo- 

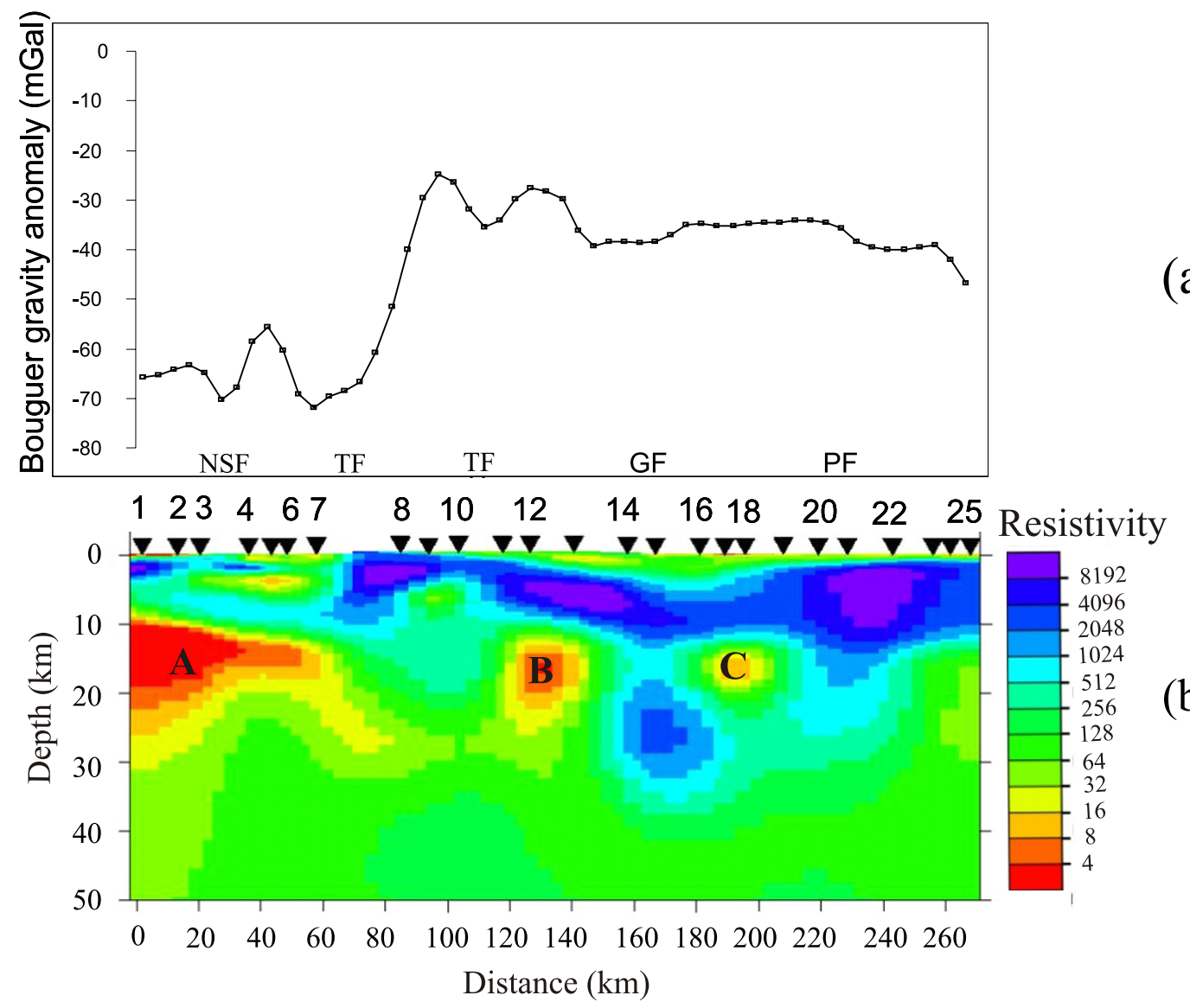

(a)
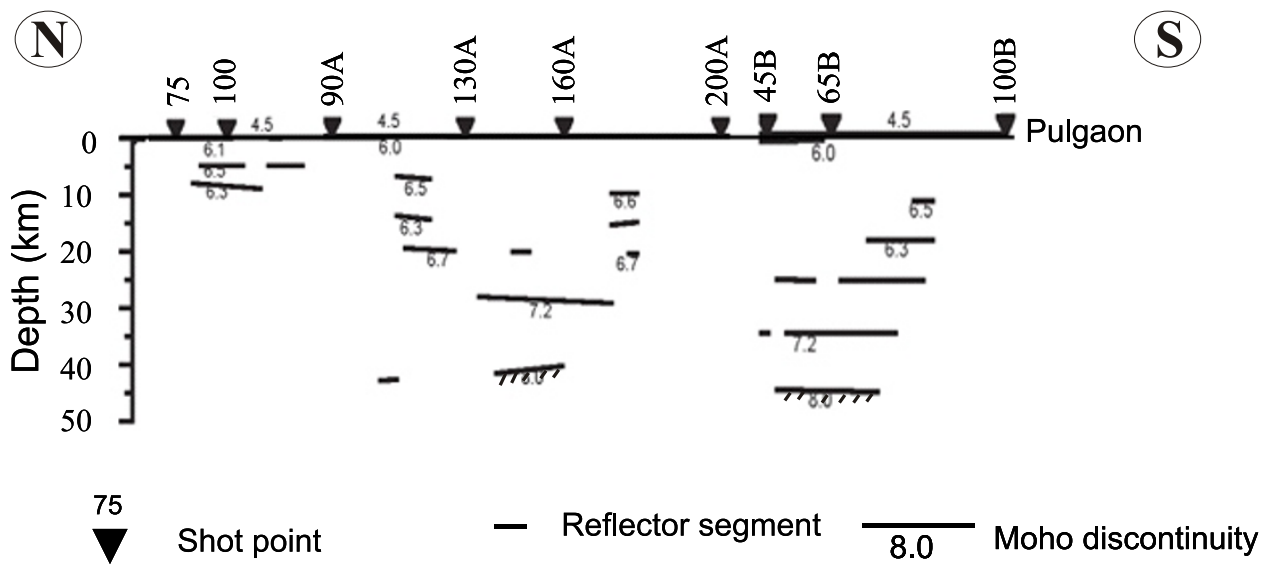

Fig. 4. The Bouguer gravity anomaly (a) plotted over the deep geoelectric crustal section (b). The deep seismic section (c) with Moho and deep seated fault features (after Tewari and Prakash Kumar, 2003). A basin like structure can also be seen between stations 11 and 21 at shallow depths (b).

electric section. The results clearly infer that the faults are close to the anomalous conductive features (A, B and C). This is more prominent near the Narmada south fault towards the northern part, as compared with the southern part of the traverse at mid-lower crustal depths. The conductive features at upper-mid crustal depths obtained from the geo-electric section spatially correlates with the absence of reflections and an indication of low seismic velocity in the Deep Seismic Sounding section (Fig. 4(c)). The gravity is low near the anomalous conductor A (Fig. 4(b)). Though the Deep Seismic Sounding study does not provide any suggestions regarding low gravity and high conductivity, it can be assumed to be of low seismic velocity. Together, these three observations suggest that the reasons for the anoma- lous conductive features (A, B and C) can be attributed to any one of the factors such as graphite, minerals, fluids or partial melt (Patro et al., 2005) as explained below.

\subsection{Graphite boundary films}

Graphite boundary films are often a probable candidate for high electrical conductivity in the lower crustal depths (Frost et al., 1989). Graphite is stable only at low oxygen fugacity in the stable continental regions. However, the present study region (NSL) is not a stable zone; it is a rift zone and active since Precambrian times. Hence, the existence of graphite in the NSL zone is not certain.

\subsection{Conducting minerals}

Metallic ore minerals, such as iron and copper sulphides, can produce high electrical conductivity $(100 \mathrm{ohm}-\mathrm{m})$ at 


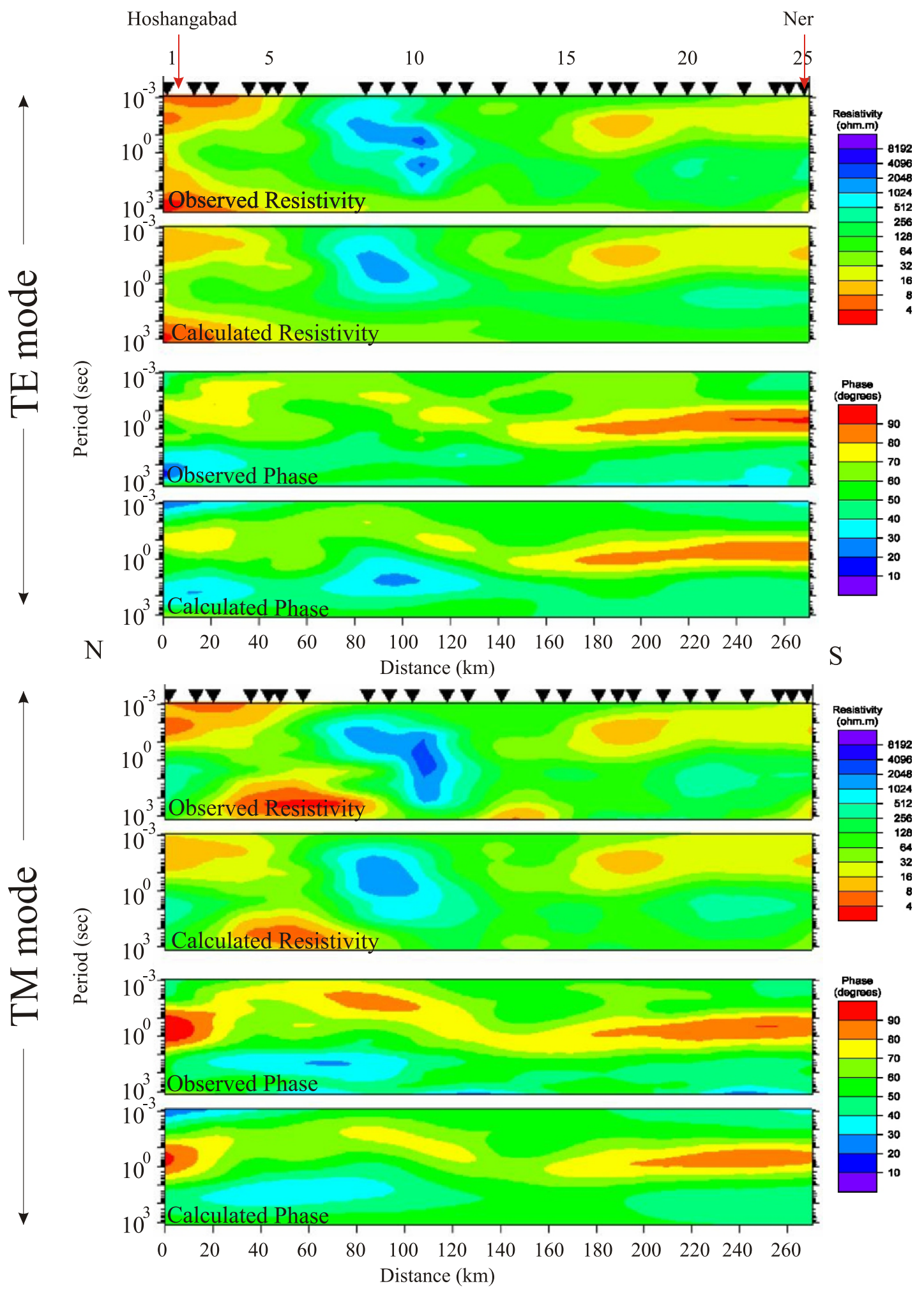

Fig. 5. The observed and computed pseudo-sections for apparent resistivity and phase data in TE and TM modes.

mid-crustal depths, while they often occur in discrete ore bodies and also disseminated over a large volume (Li et al., 2003). A large-scale mineral deposit would probably produce detectable gravity and magnetic anomalies. However, in the absence of evidence for the occurrence of such largescale mineral deposits in the study area, we can rule out this factor as a reason for the high electrical conductivity in the NSL zone.

\subsection{Fluids}

In active subduction zones, at lower crustal depths, saline fluids can produce high electrical conductivity (Hyndman and Hyndman, 1968; Brace, 1971). A large amount of water is available in subduction zones at depths less than $40 \mathrm{~km}$, from the expulsion of pore waters and from $\mathrm{CH}_{4}-\mathrm{H}_{2} \mathrm{O}$ fluids produced by diagenetic and low-grade metamorphic reactions (Peacock, 1990). However, the NSL zone is a rift 


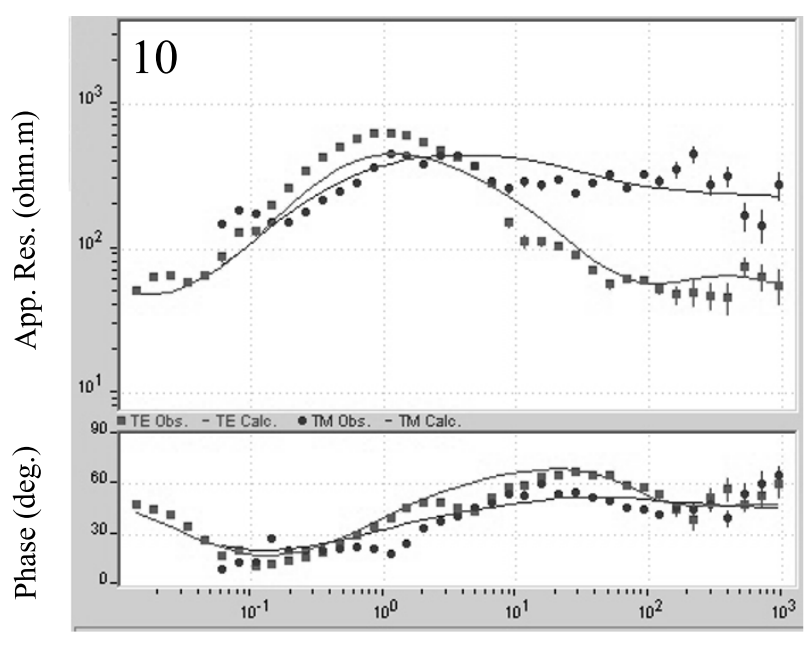

Period (s)

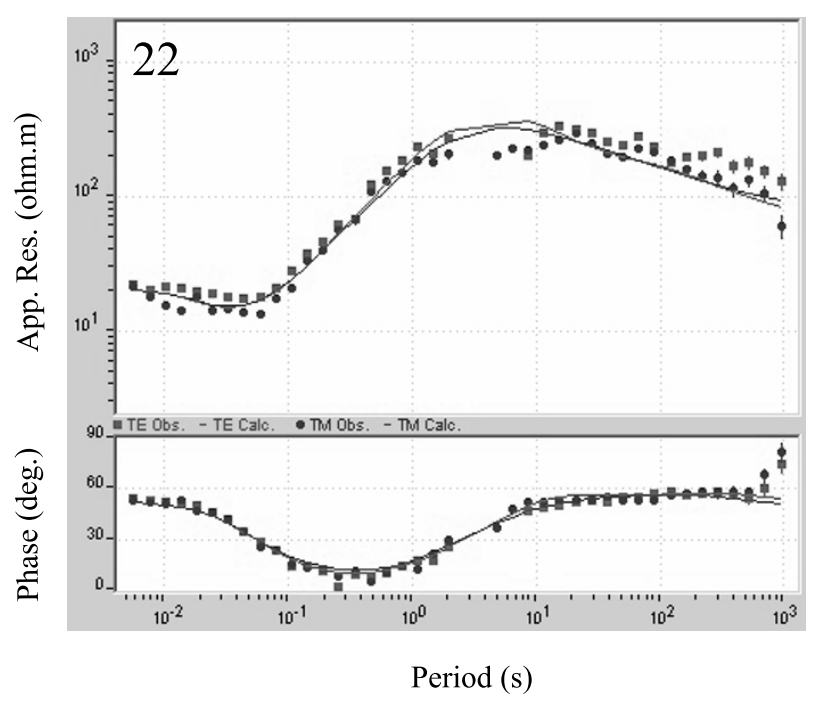

Observed - TE

Calculated - TE

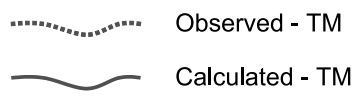

Fig. 6. The data fit between observed and calculated apparent resistivity and phase for the stations 10 and 22 .

zone and not a subduction zone. Hence, fluids are unlikely to be a probable candidate for producing the high electrical conductivity in the NSL zone.

\subsection{Partial melting}

Dry rocks begin to melt at around $1200^{\circ} \mathrm{C}$ and would produce high electrical conductivity. Partial melts, in most cases, are associated with a low seismic velocity and low gravity (Schilling et al., 1997). Hence, the low crustal seismic velocity in the study region with the absence of reflections starting from shallow depths to mid-lower crustal depths, and the low gravity anomaly, could be evidence to infer that the presence of partial melting could be a favorable source of observed crustal conductors. The partial melting of subsurface rocks may be due to high temperature and pressure conditions at mid-lower crustal depths that could be caused by mantle upwarping due to tectonic activity in the NSL zone. Additionally, this zone is considered to be a high heat flow zone (Ravi Shankar, 1988).

MT modeling results brought out three high conductive structural features (A, B and C) extending from mid to lower crustal depths. These features can be interpreted as the electrical signatures responsible for the geologicallymapped major tectonic faults, namely, the Narmada South, Tapti, Gavligarh and Purna faults as they occur in their vicinity. The distribution of the epicenters ( $>M 5.0)$ along the faults in the area suggests that the origin of the earthquakes are probably related to the faults which are conductive in nature. Rapid crustal erosion must have been taken place due to a high-temperature partial melt (where conductivity is high) in the northern part which causes faulting along pre-existing zones of weakness. The block movement along the faults could generate an earthquake. The Narmada South fault is more prominent and active compared with the other fault features, and is associated with the $M 6.0 \mathrm{Ja}$ balpur earthquake on 22 May, 1997 (Rastogi, 1997) in the study region. Thus, the present study helps in understanding the tectonic features and their nature in the NSL region.
Acknowledgments. We thank Dr. V. P. Dimri, former Director, and Dr. Y. J. Bhaskar Rao, the acting Director, of NGRI for giving permission to publish this work. The authors are thankful to Prof. Heinrich Brasse and an anonymous reviewer for their critical comments and valuable suggestions on earlier versions of the manuscript which has greatly helped to improve the manuscript. We are also thankful to Makoto Uyeshima, editor of the journal for his support during the editorial process. We also would like to thank Shri. D. N. Murthy for useful discussions and all the help regarding the modeling work. G. Dhanunjaya Naidu thanks CSIR for the Senior Research Fellowship.

\section{References}

Bahr, K., Interpretation of magnetotelluric impedance tensor: regional induction and local telluric distortion, J. Geophys., 62, 119-127, 1988.

Brace, W. F., Resistivity of saturated crustal rocks to $40 \mathrm{~km}$ based on laboratory measurements, in Structure and Physical Properties of the Earth's Crust, edited by Heacock, J. G., 14, 206-210, AGU Geophys. Monogr. Ser., 1971.

Frost, B. R., W. S. Fyfe, K. Tazaki, and T. Chan, Grain-boundary graphite in rocks and implications for high electrical conductivity in the lower crust, Nature, 340, 134-136, 1989.

Geological Survey of India, Seismotectonic Atlas of India and Its Environs, 2000.

Ghosh, D. B., The nature of the Narmada-Son lineament, Geol. Soc. Ind., Publ., 34, Pt. III, 1976.

Gokarn, S. G., C. K. Rao, G. Gupta, B. P. Singh, and M. Yamashita, Deep crustal structure in central India using magnetotelluric studies, Geophys. J. Int., 144, 685-694, 2001.

Groom, R. W. and R. C. Bailey, Decomposition of magnetotelluric impedance tensor in the presence of local three-dimensional galvanic distortion, J. Geophys. Res., 94, 1913-1925, 1989.

Hansen, P. C., Rank deficient and discrete Ill—Posed problems, numerical aspects of linear inversion, SIAM, Philadelphia, 1998.

Harinarayana, T., B. P. K. Patro, K. Veeraswamy, C. Manoj, K. Naganjaneyulu, D. N. Murthy, and G. Virupakshi, Regional Geo-electric structure beneath Deccan volcanic province of the Indian subcontinent using magnetotellurics, Tectonophysics, 445, 66-80, 2007.

Hyndman, R. D. and D. W. Hyndman, Water saturation and high electrical conductivity in the lower crust, Earth Planet. Sci. Lett., 4, 427-432, 1968.

Jain, A. K., N. Annup, and D. C. Singhal, Crustal evolution of the Narmada- Son lineament and associated shear zones of the Indian lithosphere, J. Earth. Sci., CEISM Seminar, 125-148, 1984.

Jupp, D. L. B. and K. Vozoff, The magnetotelluric method in the explo- 
ration of sedimentary basins-Discussion, Geophysics, 62(2), 692-692, 1997.

Kaila, K. L., P. R. Reddy, M. M. Dixit, and P. Koteswar Rao, Crustal structure across the Narmada-Son lineament, Central India from deep seismic soundings, J. Geol. Soc. India., 26, 465-480, 1985.

Li, S., M. J. Unsworth, J. R. Booker, W. Wei, H. Tan, and A. G. Jones, Partial melt or aqueous fluid in the mid-crust of Southern Tibet? Constraints from INDEPTH Magnetotelluric data, Geophys. J. Int., 153, 289-304, 2003.

Mall, D. M., A. P. Singh, and D. Sarkar, Structure and tectonics of satpura, central India, Curr. Sci., 88(10), 1621-1627, 2005.

Naganjaneyulu, K. and M. Santosh, The Central India Tectonic Zone: a geophysical perspective on continental amalgamation along a Mesoproterozoic suture, Gondwana Res., 18, 547-564, 2010.

Naidu, G. D. and T. Harinarayana, Deep electrical imaging of the Narmada-Tapti region, central India from magnetotellurics, Tectonophysics, 2009.

NGRI, Bouguer gravity anomaly (Terrain corrected) Map of India, A collaborative project of Geological survey of India, National Geophysical Research Institute, Oil and Natural Gas Commission Limited, Survey of India, Oil India Limited, 2006.

Patro, B. P. K., T. Harinarayana, R. S. Sastry, Madhusushana Rao, C. Manoj, K. Naganjaneyulu, and S. V. S. Sarma, Electrical imaging of Narmada-Son Lineament Zone, Central India from magnetotellurics, Phys. Earth Planet. Inter., 48, 215-232, 2005.

Patro, P. K. and S. V. S. Sarma, Lithospheric electrical imaging of the Deccan trap covered region of western India, J. Geophys. Res., 114, B01102, 2009.

Peacock, S. M., Fluid processes in subduction zones, Science, 248, 329337, 1990.

Ramalingeswara Rao, B. and P. Sitapathi Rao, Historical seismicity of Peninsular India, Bull. Seismol. Soc. Am., 74, 2519-2533, 1984.
Rao, C. K., Y. Ogawa, S. G. Gokarn, and G. Gupta, Electromagnetic imaging of magma across the Narmada Son lineament, central India, Earth Planets Space, 56, 229-238, 2004.

Rastogi, B. K., Seismo-tectonics along Narmada-Son rift zone, Proceedings of Workshop on the Tectonics of Narmada-Son Lineament, 37-49 (Misc. Publ. No. 63), 1997.

Ravi Shanker, Heat flow map of India and discussion on its geological and economic significance, Indian Minerals, 42, 89-110, 1988.

Rodi, W. and R. L. Mackie, Nonlinear conjugate gradients algorithm for 2D magnetotelluric inversions, Geophysics, 66, 174-187, 2001.

Schilling, F. R., G. M. Partzsch, H. Brasse, and G. Schwarz, Partial melting below the magmatic arc in the central Andes deduced from geo-electromagnetic field experiments and laboratory data, Phys. Earth Planet. Inter., 103, 17-31, 1997.

Singh, A. P. and R. Meissner, Crustal configuration of the Narmada-Tapti region (India) from gravity studies, J. Geodyn., 20, 111-127, 1995.

Swift, Jr., C. M., A magnetotelluric investigation of electrical conductivity anomaly in the southwestern United States, Ph.D. thesis, MIT, 1967.

Tewari, H. C. and Prakash Kumar, Deep seismic sounding studies and its tectonic implications, J. Virtual Explor., 12, 30-54, 2003.

Verma, R. K. and P. Banerjee, Nature of continental crust along the Narmada-Son lineament, inferred from gravity and deep seismic sounding data, Tectonophysics, 202, 375-397, 1992.

Wellman, P. and M. W. Mc Elhinny, K-Ar age of the Deccan traps, India, Nature, 227, 595-596, 1970.

West, W. D., The line of the Narmada and Son valleys, Cur. Sci., 31, 143144, 1962.

G. D. Naidu (e-mail: dhanugeo@yahoo.co.in), K. Veeraswamy, and T. Harinarayana 